\title{
Development and application of molecular and bioinformatic tools for the genetic monitoring of beets
}

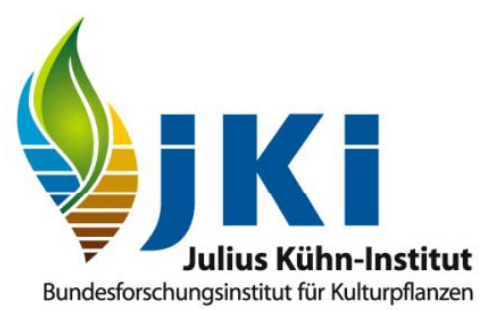

Matthias Enders, Lothar Frese, Marion Nachtigall
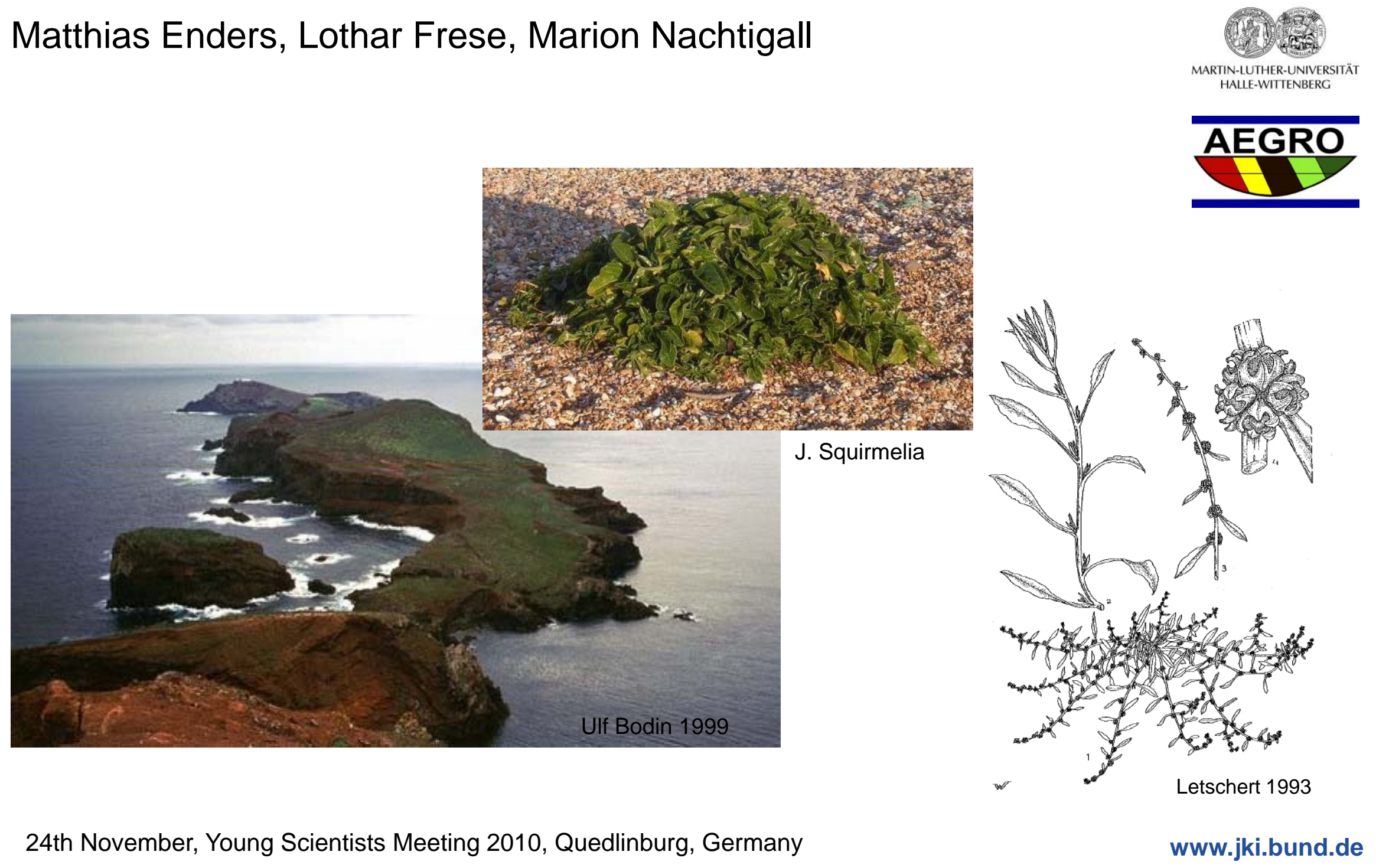

24th November, Young Scientists Meeting 2010, Quedlinburg, Germany

www.jki.bund.de 
Diversity analysis: Beta patula (Ait.) (BP)

Objective: Create decision criteria required for the establishment of a genetic reserve for $B$. patula of a genetic reserve for B. patula

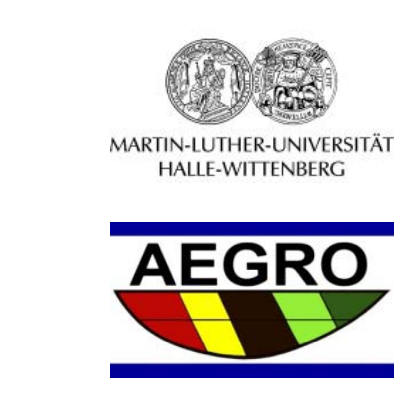

\section{Diversity analysis: Beta vulgaris (L.) ssp. maritima (Arcang.) (BVM)}

Objective: Analysis of the genetic structure as a basis for further investigations on In-situ-conservation strategies

$>$ Design and implementation of a database

Objective: Development of tools for data storage and the analysis of time series within the framework of genetic monitoring 


\section{Overview}

\section{Introduction}

2. Material and methods

3. Diversity studies (B. patula, B. vul. ssp. maritima)

4. Monitoring database 
Crop Wild Relatives (CWR) are species closely related to crops that include crop progenitors, and that may contribute beneficial traits to crops [...] (Maxted et al. 2008)

Plant genetic resources (PGR) are part of the biological resources and defined as [...] genetic material of actual or potential value [...] (BGB, 1993, Nr. 32)

\section{Convention on Biological Diversity, CBD}

National Strategy on Biological Diversity Federal Ministry for Environment, Nature conservation and Nuclear Safety, FRG

Agro-biodiversity strategy

Federal Ministry of Food, Agriculture and Consumer Protection, FRG

Law about the Convention on Biological Diversity Article 8:

In-situ Conservation should be used to [...] Regulate or manage biological resources $[\ldots]$ 
Ex-situ: In-situ:

Genebank genetic reserve conservation technique

Genetic reserve conservation technique:

Conservation of wild species in a genetic reserve involves the location, designation, management and monitoring of genetic diversity in a particular, natural location (Maxted et al. 1997).

\section{AEGRO:}

„An Integrated European In Situ Management Work Plan: Implementing Genetic Reserves and On Farm Concepts“ (2007-2011)

AEGRO creates the data- and knowlege baseline for the establishment of genetic reserves for selected crop genepools. This work conforms to target 7 of the 10. Conference of Parties of the CBD (Nagoya, 2010) 


\section{Overview}

1. Introduction

2. Material and methods

3. Diversity studies (B. patula, B. vul. ssp. maritima)

4. Monitoring database

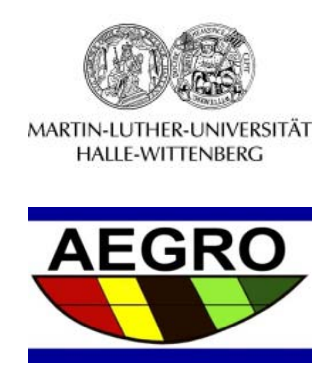


An endemic species distributed on two islets off Madeira

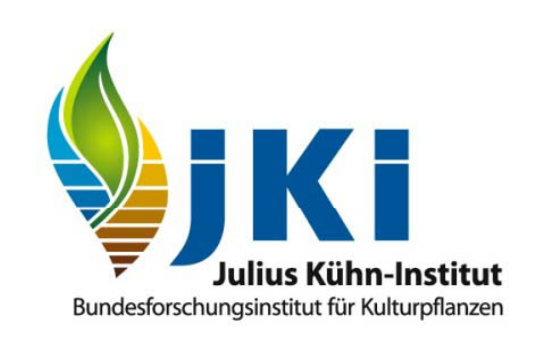

\section{Ilhèu do Desembarcadouro}
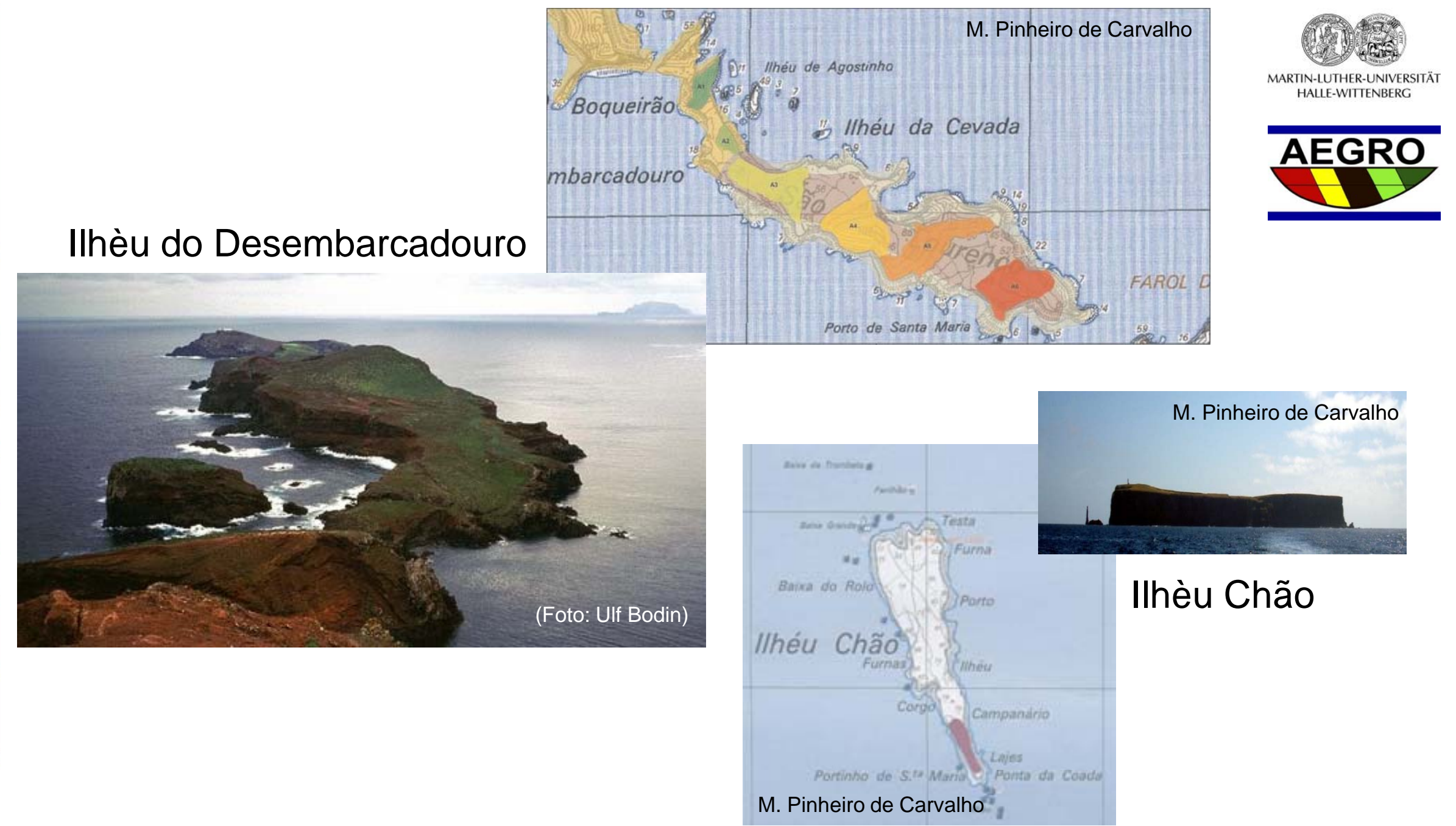

24th November, Young Scientists Meeting 2010, Quedlinburg, Germany 
Distributed along the Mediterranean Basin, the European Atlantic sea shores as well as in the western part of the Baltic Sea area

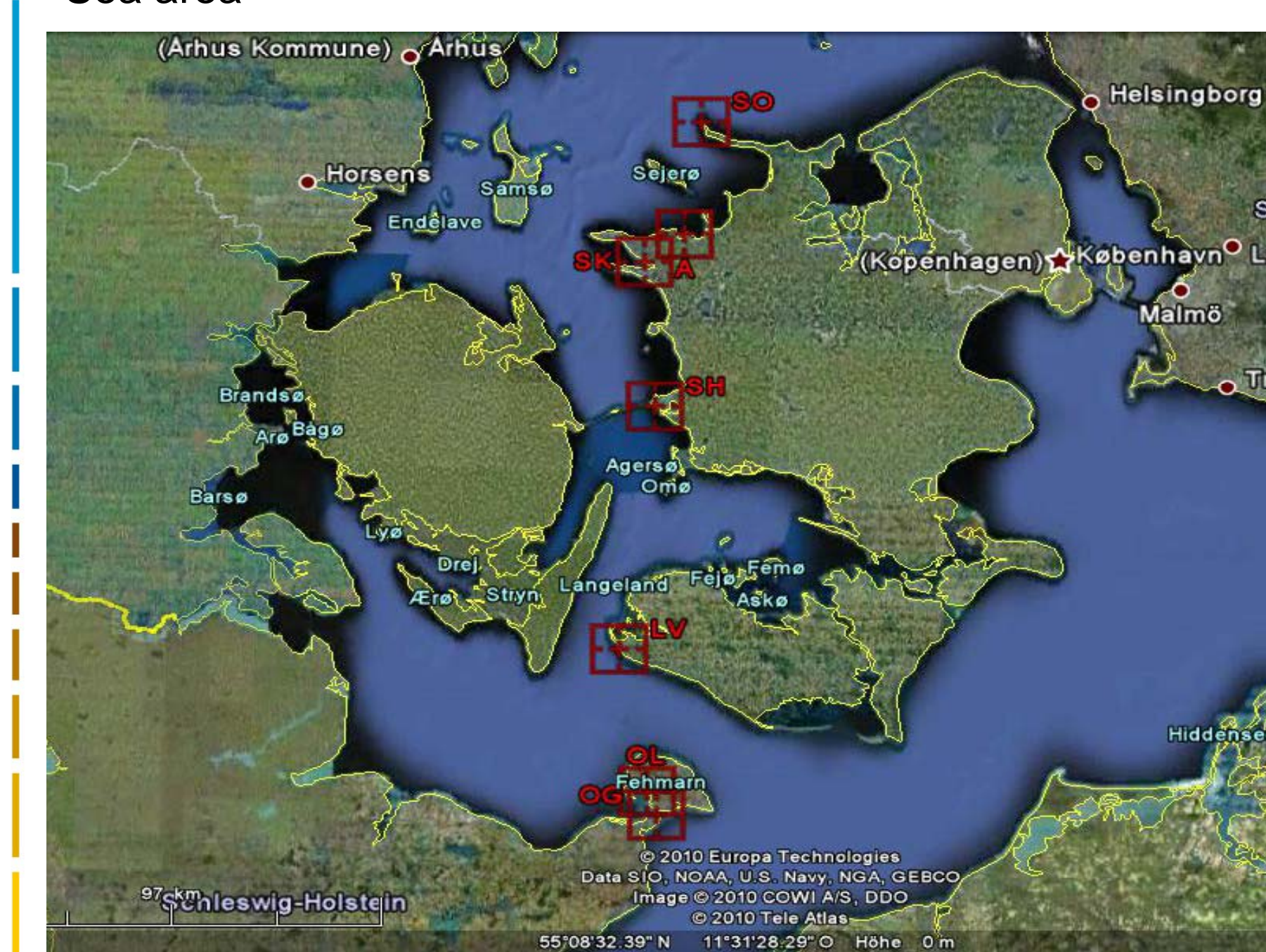

(Google Earth ${ }^{\mathrm{TM}}-$ Kartenservice) 24th November, Young Scientists Meeting 2010, Quedlinburg, Germany

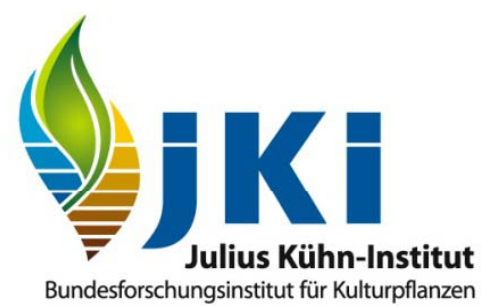

Bundesforschungsinstitut für Kulturpflanzen

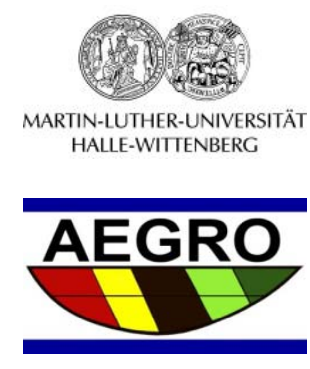

\section{Motivation:}

-Will the global climate change shift the distribution area towards the northern latitude and how will this affect genetic diversity?

-How will the loss of habitats in the South and gain in the North influence the conservation of important traits for breeding? 
- 25 SSR markers covering all linkage groups

- Approximately 2 SSR markers for each linkage group

- 242 samples of $B$. patula were collected in the natural habitat

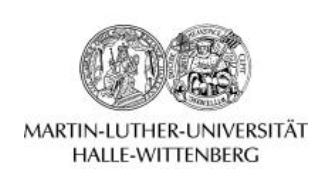

- 316 samples of $B$. vul. ssp. maritima were sampled in the natural habitat

- All sampling plots were georeferenced

- Coordinates of 227 individual plants for B. vul. ssp. maritima were registered 
1. Introduction

2. Material and Methods

3. Diversity studies (B. patula, B. vul. ssp. maritima)

4. Monitoring database

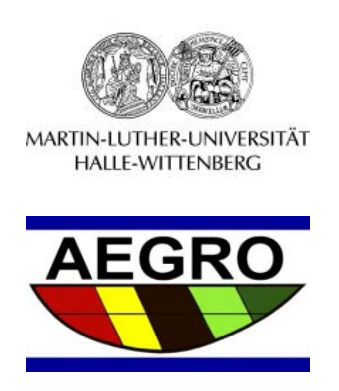




\section{B. patula diversity study}

Factorial analysis Axes1/2

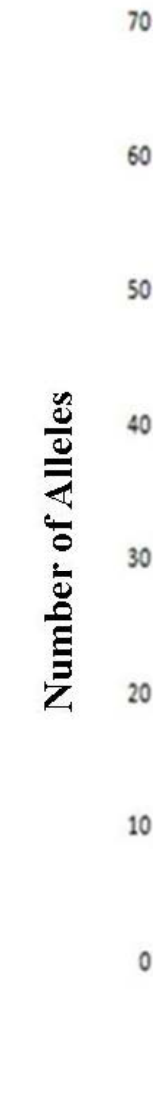

0

$42,48 \%$

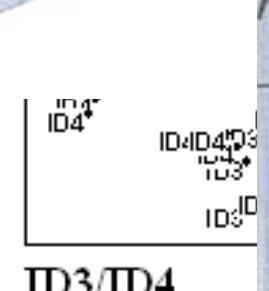

RP3 / RP4

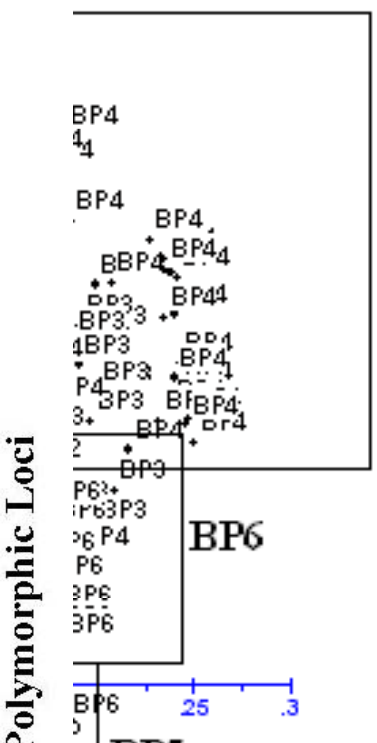

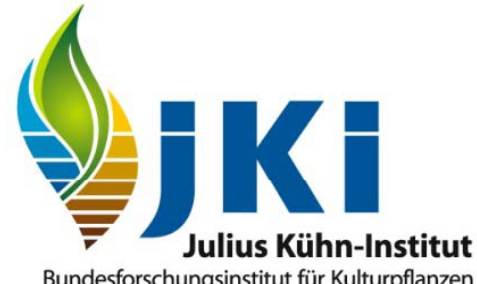
Bundesforschungsinstitut für Kulturpflanzen

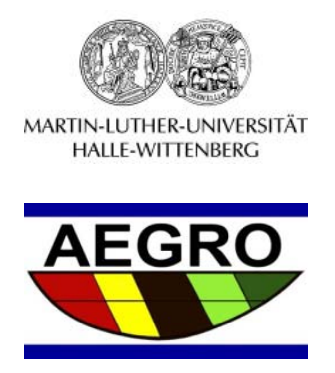

mbarcadouro

Perriar $\times$ lacquemoud-Collet, J.P.

2) Ilhéu da Cevada

(2006). DARwin coftware

genetic ad /darwin reserve

Porto de Santa Maria 


\section{B. vul. ssp. maritima diversity study}

Factorial analysis: Axes $1 / 2$

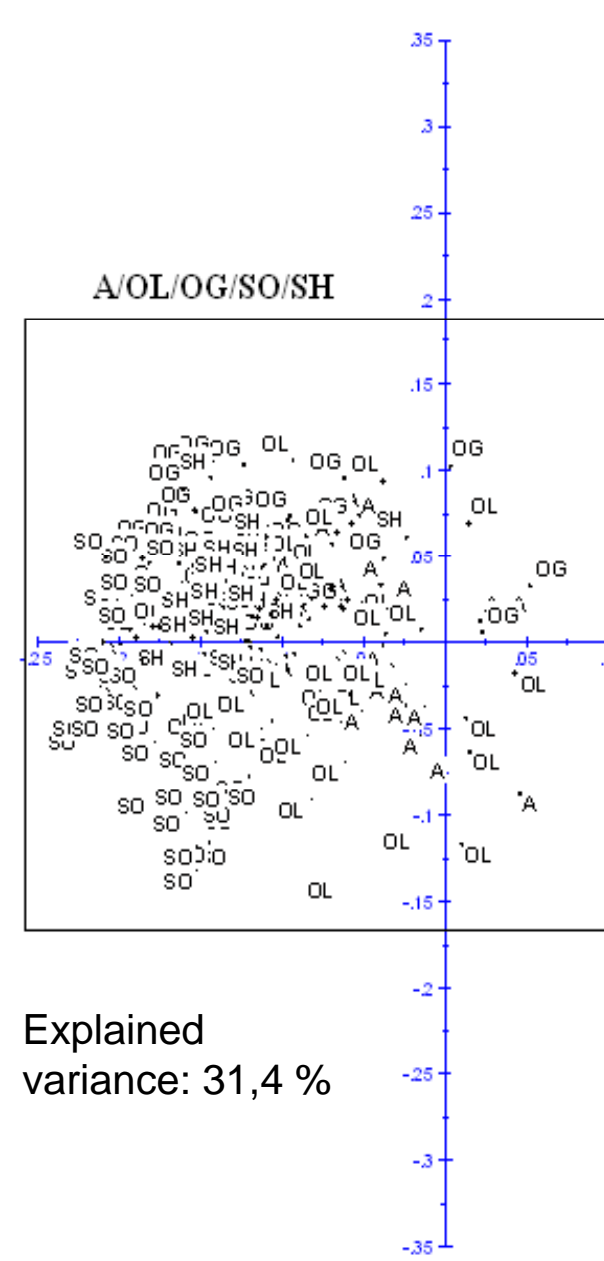

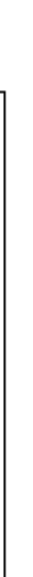
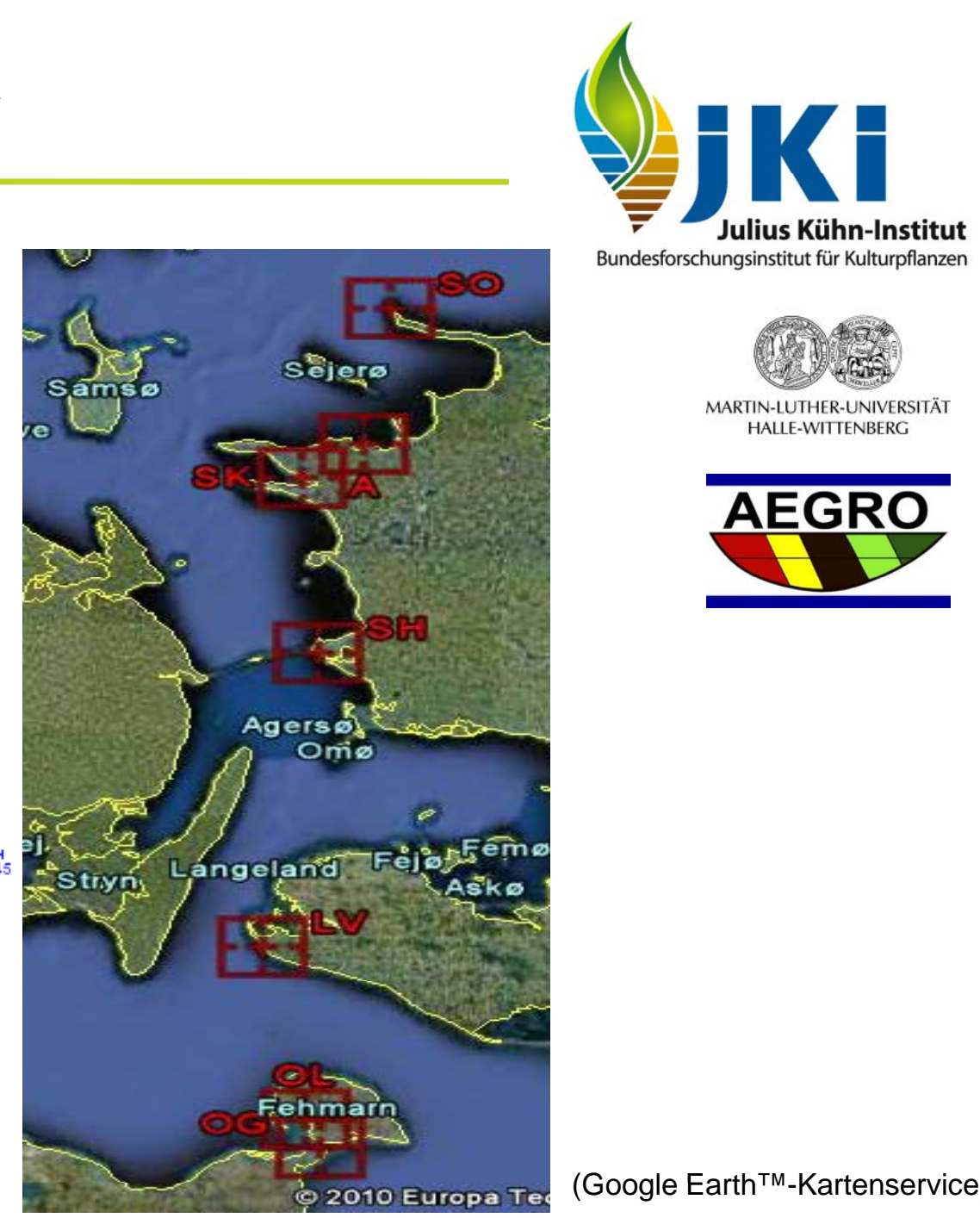
Bundesforschungsinstitut für Kulturpflanzen

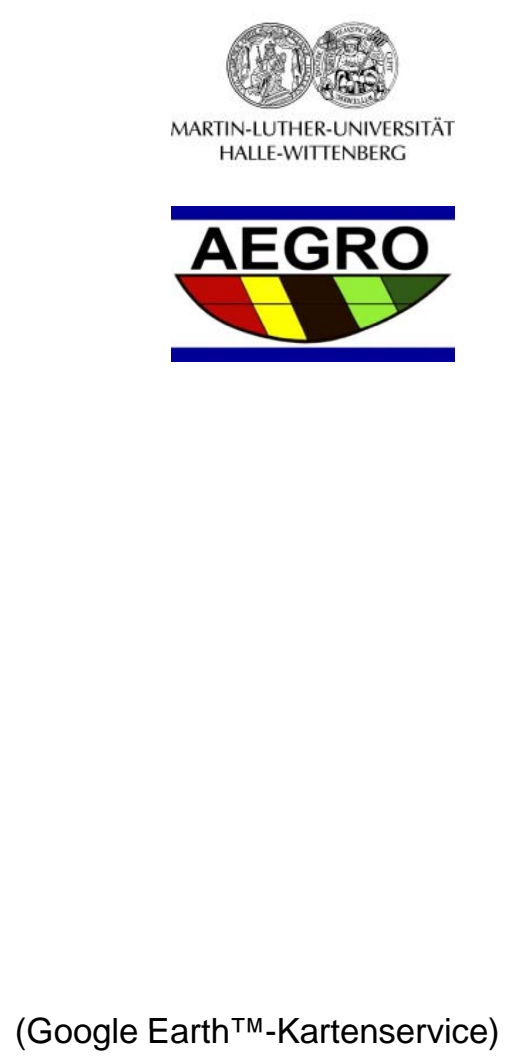

Perrier, X., Jacquemoud-Collet, J.P. (2006). DARwin software

http://darwin.cirad.fr/darwin 
Geneland (Guillot et al. Mol. Ecol. Notes 5, 712-715, 2005)

- assigns individuals to clusters and identifies migrants

- investigates the most likely number of populations

- combines geographic coordinates with a colored probability map of the cluster membership

Probability of the membership of individuals to a cluster
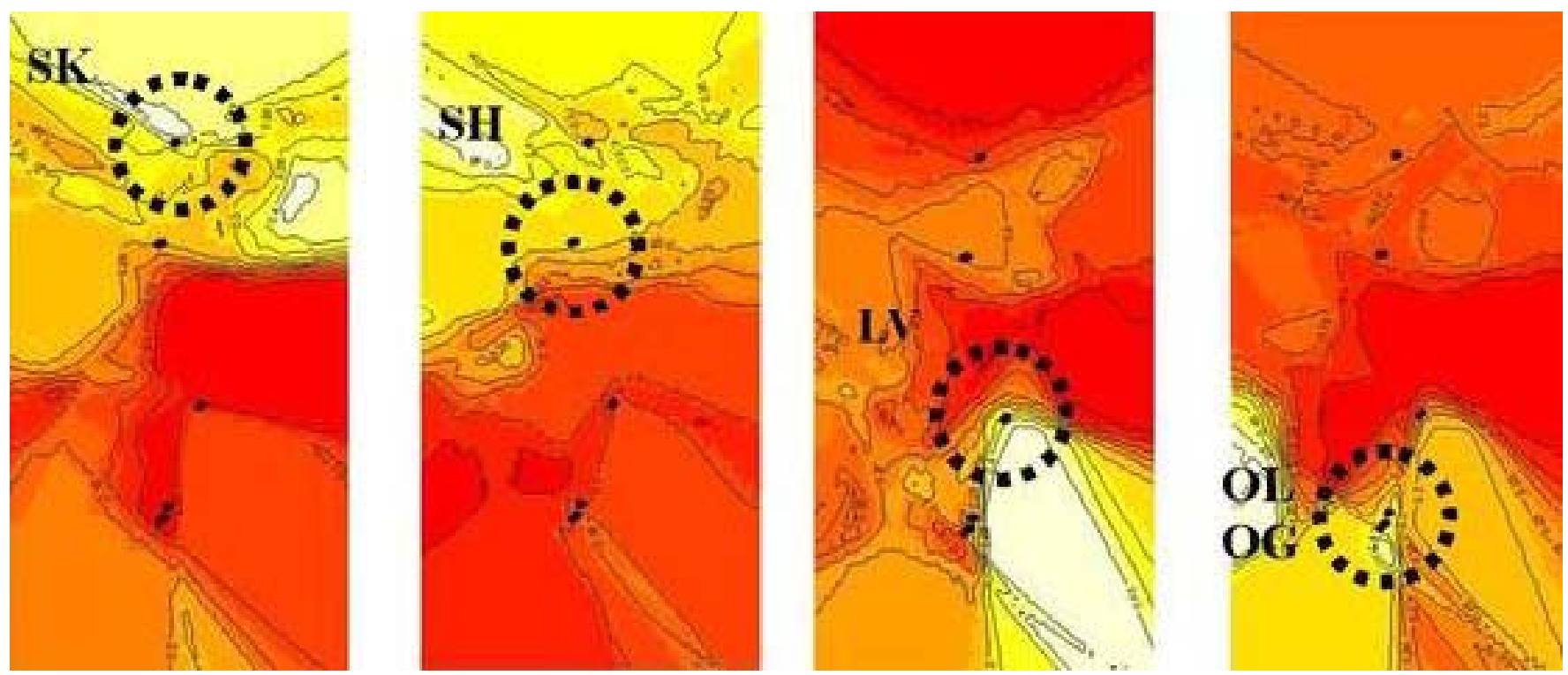

Propability

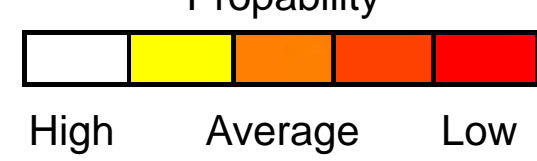

24th November, Young Scientists Meeting 2010, Quedlinburg, Germany 


\section{Overview}

1. Introduction

2. Material and Methods

3. Diversity studies (B. patula, Beta vul. ssp. maritima)

4. Monitoring database 


\section{Monitoring database}

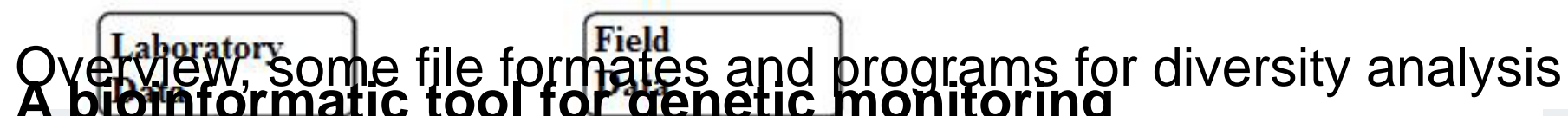

\section{A bibinformatic tool forgenetic monitoring}

- Storage of laboratory and field data associated wittorgenetictice monitoring

- Basis for cuinparisons of data gathered în Anplications Series

- Tool for editing and formating the data
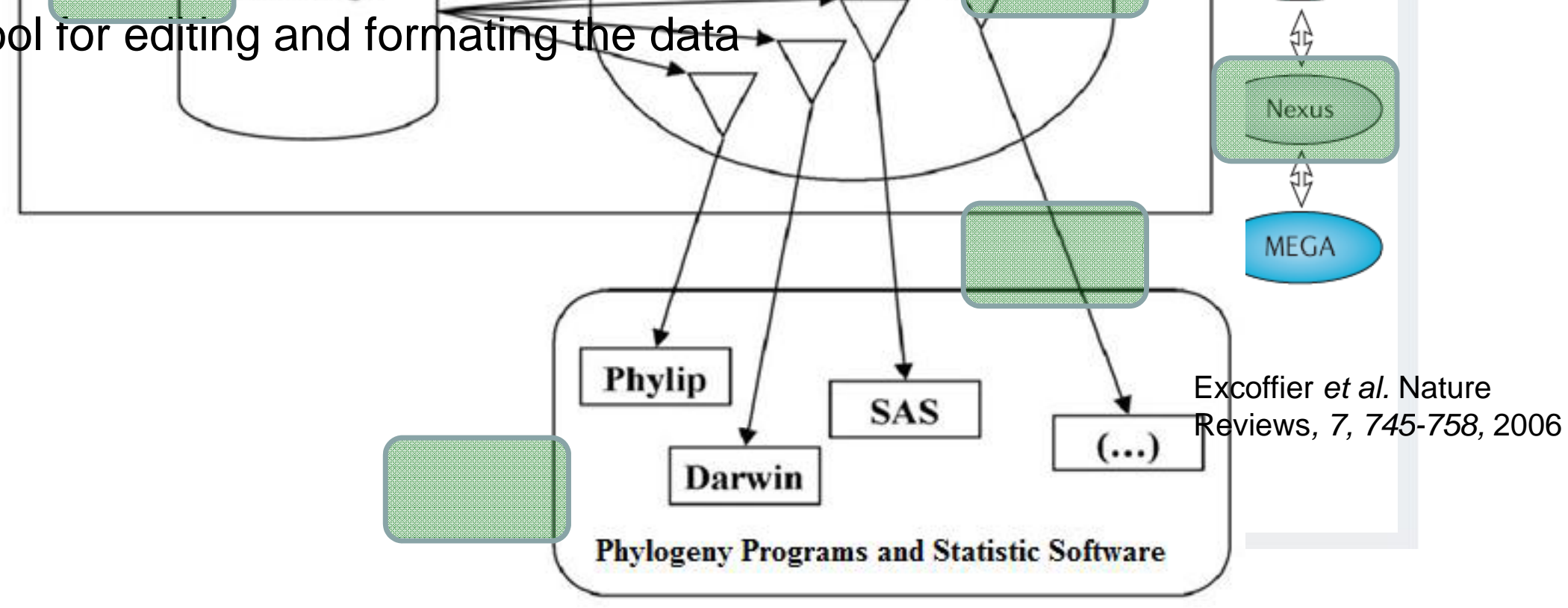


\section{Summary}

- First description of the geographic patterns of genetic diversity in the wild beet $B$. patula

- Genetic data required as decision criteria for the establishment of a genetic reserve for $B$. patula were produced.

- Consolidation of the knowledge of geographic patterns of genetic diversity in the wild beet $B$. vul. ssp. maritima. This gives a baseline for further examinations on the potential influence of the geographic range shift on genetic diversity.

- Development of a database capable to store and process field and laboratory data associated with genetic monitoring 


\section{Acknowledgement}

Dr. Lothar Frese, Dr. Marion Nachtigall (topic, material, assistance)

Petra Hertling, Uta Brunngräber (support and technical assistence)

Dr. Edgar Schliephake (statistics and mathematics)

Dr. Christoph Germeier (software development)
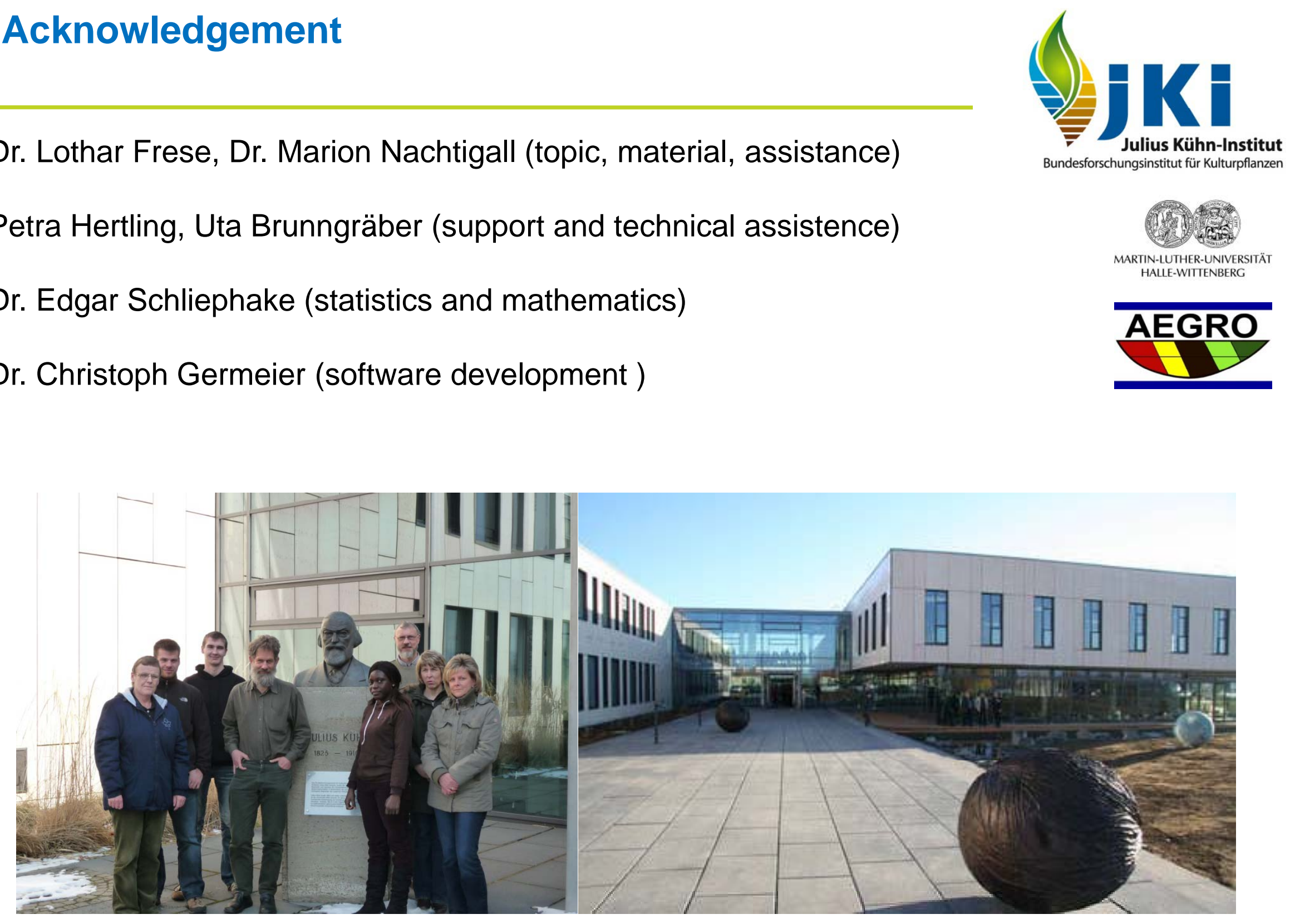